\title{
Sistematización de la prevalencia de Anaplasma spp., en caninos y metanálisis de $A$. platys y $A$. phagocytophilum
}

\author{
Jaiberth Cardona-Arias ${ }^{1,3 *} \bowtie \mathbb{B}$ M.Sc; Juliana Zapata Marín² $₫ \mathbb{B}$ MyB; Johanna Marcela Urán ${ }^{1} \bowtie \mathbb{B}$ M.Sc.
}

${ }^{1}$ Universidad de Antioquia UdeA, Escuela de Microbiología. Medellín, Colombia.

2Universidad de Antioquia UdeA, Escuela de Microbiología, Grupo de investigación Salud y Sostenibilidad. Medellín, Colombia.

3Universidad Cooperativa de Colombia, Medellín, Colombia.

*Correspondencia. jaiberth.cardona@udea.edu.co

Recibido: Julio 2018; Aceptado: Marzo 2019; Publicado: Mayo 2019.

\section{RESUMEN}

Objetivo. Estimar la prevalencia general de Anaplasma spp. y la prevalencia específica de $A$. platys y A. phagocytophilum en caninos, mediante estudios publicados entre 2000 y 2018. Materiales y métodos. Revisión sistemática con 14 estrategias de búsqueda, garantizando exhaustividad y reproducibilidad en fases de la guía PRISMA. Se evaluó la calidad con STROBE. Se calcularon frecuencias y se estimó la prevalencia global y las específicas según país, periodo y prueba diagnóstica, con sus intervalos de confianza del 95\%. Se realizó Forest Plot para la prevalencia individual y global de A. platys o A. phagocytophilum según PCR, ELISA e IFI, las cuales se compararon con base en el Estadístico Z. Resultados. Se incluyeron 30 estudios con 18.472 caninos, la mayoría de Brasil, Estados Unidos y Alemania. En IFI se halló una prevalencia de 39.0\% (IC95\%=37.0-41.0), en ELISA 9.3\% (IC95\%= 8.8-9.8) y en PCR 7.1\% (IC95\%= 6.4-7.8). La prevalencia basada en PCR fue estadísticamente mayor en América con $11.9 \%$ (IC95\%=10.5-13.3) frente a África con 5.5\% (IC95\%=1.2-9.7), Asia 4.1\% (IC95\%=3.1-5.1) y Europa 3.5\% (IC95\%=2.5-4.5). La prevalencia de A. platys con PCR fue $16.1 \%($ IC $95 \%=14.2-17.9)$ y de $A$. phagocytophilum $3.7 \%($ IC $95 \%=2.8-4.6)$. Conclusiones. Se halló una elevada prevalencia de infección, con mayor importancia de $A$. platys, en un bajo número de publicaciones en el ámbito mundial y con una elevada heterogeneidad según el país, la técnica diagnóstica y la especie implicada.

Palabras clave: Anaplasma, caninos, metanálisis, prevalencia (Fuente: DeCS).

\begin{abstract}
Objective. To estimate the general prevalence of Anaplasma spp. and specific prevalence of $A$. platys and $A$. phagocytophilum in canines, through studies published between 2000 and 2018. Material and methods. Systematic review with 14 search strategies, guaranteeing completeness and reproducibility according PRISMA. Quality was evaluated with STROBE. The global prevalence and the specific ones were estimated according to country, period and diagnostic test, with their confidence intervals of $95 \%$. Forest Plot was performed for the individual and global prevalence of $A$ platys or $A$. phagocytophilum according to PCR, ELISA and IFI, which were compared based on Statistic Z. Results. Thirty studies were included with 18472 canines, mostly from Brazil, United States and Germany. In IFI the prevalence was $39.0 \%(95 \% \mathrm{CI}=37.0-41.0)$, in ELISA $9.3 \%(95 \% \mathrm{CI}=8.8-9.8)$ and in CRP $7.1 \%(95 \%$ $\mathrm{CI}=6.4-7.8)$. The prevalence based on CRP was statistically greater in America with $11.9 \%(95 \% \mathrm{CI}=10.5-13.3)$ compared to $5.5 \%$ in Africa $(95 \% \mathrm{CI}=1.2-9.7)$, Asia $4.1 \%(95 \% \mathrm{CI}=3.1-5.1)$ and Europe $3.5 \%(95 \% \mathrm{CI}=2.5-4.5)$. The prevalence of $A$. platys with CRP was $16.1 \%$ (IC95\% $=14.2-17.9)$ and of $A$. phagocytophilum $3.7 \%(95 \%$ CI $=$ 2.8-4.6). Conclusions. A high prevalence of global infection was found, with greater importance of $A$. platys, in a low number of publications worldwide and with a high heterogeneity according to the country, the diagnostic technique and the species involved.
\end{abstract}

Keywords: Anaplasma, canines, meta-analysis, prevalence (Source: DeCS).

Como citar (Vancouver)

Cardona-Arias J, Zapata MJ, Marcela UJ. Sistematización de la prevalencia de Anaplasma spp., en caninos y metanálisis de $A$. platys y A. phagocytophilum. Rev MVZ Cordoba. 2019; 24(2):7239-7247. DOI: https://doi.org/10.21897/rmvz.1310

(C)EI (los) autor (es), Revista MVZ Córdoba 2019. Este artículo se distribuye bajo los términos de la licencia internacional Creative Commons Attribution 4.0 (https://creativecommons.org/licenses/by-sa/4.0/), que permite el uso sin restricciones, la distribución y la reproducción en cualquier medio, siempre que se otorgue el crédito apropiado al autor o autores originales y la fuente. 


\section{INTRODUCCIÓN}

La anaplasmosis es una enfermedad infecciosa hemoparasitaria producida por bacterias gram negativas, intracelulares obligadas, inmóviles, de morfología cocoide; su blanco son las células hematopoyéticas (especialmente neutrófilos y plaquetas), se replican dentro de una vacuola derivada de la membrana de la célula eucariota del hospedero, vertebrado o invertebrado. Generalmente es transmitida por artrópodos, pueden afectar a humanos y numerosas especies de animales domésticos y silvestres, entre las que se reportan perros, caballos, cabras, ovejas, gatos, rumiantes, aves, entre otros que podrían desempeñar un papel importante en la persistencia y diseminación de la enfermedad $(1,2)$.

La anaplasmosis se presenta en áreas tropicales y subtropicales con las condiciones que favorecen la supervivencia y reproducción del vector. Es es endémica en regiones del Medio Oeste, Este y Noreste de los Estados Unidos, así como las regiones costeras occidentales, en donde la mayoría de los brotes son estacionales y coinciden con la aparición de garrapatas. En países como Reino Unido, Noruega, Suecia, Suiza y Alemania se han reportado infecciones en rumiantes, caninos y humanos; mientras que en Asia y Suramérica ha sido menos frecuente su estudio. La necesidad de conocer su ocurrencia y distribución radica en su importancia como enfermedad zoonótica, su amplia distribución geográfica y la complejidad de los cuadros clínicos que genera $(3,4)$. Especialmente en perros el enfoque es muy importante por el aumento de las mascotas de diferentes regiones, el elevado número de adopciones y la cercanía de los caninos con los humanos, lo que hace de esta situación un hecho epidemiológico de importancia que implica conocer a profundidad el agente implicado (5).

En los caninos los principales agentes etiológicos son Anaplasma phagocytophilum y Anaplasma platys $(6,7)$. La infección causada por $A$. phagocytophilum es transmitida por garrapatas del género Ixodes, produciendo la anaplasmosis granulocítica canina, y la infección causada por $A$. platys es transmitida principalmente por Rhipicephalus sanguineus, produciendo la Trombocitopenia Cíclica Infecciosa Canina (TCIC). Los principales signos de esta enfermedad en los perros son fiebre, depresión, cojera, anorexia, inflamación articular, signos neurológicos y cuadro hemático y uroanalisis con hallazgos de trombocitopenia, anemia no regenerativa, leucopenia, hiperglobulinemia y proteinuria durante varias etapas de infección $(8,9)$. Los signos clínicos asociados con Anaplasma spp. en ocasiones no son muy específicos; por consiguiente, se dificulta su diagnóstico clínico. Adicional a esto, algunos reportes indican que los perros infectados por $A$. platys pueden cursar con una trombocitopenia cíclica que puede ser lo suficientemente grave como para producir hemorragia, incluyendo petequias y equimosis, pero se cree que la mayoría de los perros controlan la infección inmunológicamente (10).

El diagnóstico incluye frotis sanguíneo con tinción de Giemsa, el cual presenta baja sensibilidad ante baja bacteriemia o infecciones transitorias. También se cuenta con pruebas inmunoenzimáticas e inmunofluorescentes con buena sensibilidad y especificidad, pero limitadas por el hecho que los anticuerpos generalmente están ausentes durante las dos primeras semanas de aparición de los signos de la enfermedad, persisten hasta ocho meses después de la eliminación del agente y pueden presentarse reacciones cruzadas con otros agentes de la familia Anaplasmataceae y rickettsiales (2).

Finalmente, la PCR es utilizada mundialmente como herramienta en el diagnóstico de enfermedades infecciosas y para caracterizar agentes patógenos, la utilidad de esta técnica es sustentada por la identificación rápida y precisa de enfermedades que de otro modo serían difíciles de detectar, mediante el uso de cebadores universales dirigidos contra el ADN ribosómico $16 S$ bacteriano y el análisis de secuenciación (11). Publicaciones previas han demostrado la especificidad de la PCR, baja reactividad cruzada con otras especies y buena reproducibilidad con bajos coeficientes de variación intra e inter ensayo, lo cual permite superar limitaciones de otros métodos diagnóstico, pues permite detectar y cuantificar el ADN de Anaplasma spp. en sangre canina, lo que resulta crucial para la detección, diagnóstico y seguimiento de la infección (12).

La magnitud de la infección puede presentar una elevada heterogeneidad atribuible a su carácter asintomático, hallazgos de laboratorio (hematológicos y bioquímicos) inespecíficos, variaciones en la utilidad diagnóstica de las técnicas utilizadas y factores ambientales, particularmente los relacionados con la presencia de vectores específicos que condicionan la epidemiología en diferentes regiones del mundo (13).

Por lo anterior, es relevante desarrollar una revisión sistemática que permita conocer un panorama global de la prevalencia de Anaplasma spp. en caninos, caracterizar la ocurrencia por especie de A platys o A. phagocytophilum, este último es uno de los principales patógenos causales en perros que en condición doméstica puede relacionarse con infecciones en seres humanos (14). También es relevante comparar la prevalencia según lugar, periodo de estudio y prueba diagnóstica, para orientar acciones sanitarias e investigativas posteriores. Además, las revisiones sistemáticas como una búsqueda estructurada, explícita, sistemática, exhaustiva y reproducible de estudios referidos a una pregunta de investigación, permite aumentar las posibilidades de extrapolación de resultados, mejora la precisión en la estimación y comparación de prevalencias, es una herramienta clave en la toma de decisiones en salud y en la evaluación de las necesidades de investigación, y a menudo se usan como punto de partida para el trabajo de grupos de consenso, paneles de expertos o comisiones con responsabilidades reguladoras y de alto impacto sanitario (15).

El objetivo de este estudio fue estimar la prevalencia general de Anaplasma spp. y la prevalencia específica de $A$ platys y $A$. phagocytophilum en caninos, mediante estudios publicados entre 2000 y 2018.

\section{MATERIALES Y MÉTODOS}

Tipo de estudio. Revisión sistemática de la literatura y metanálisis.

Estrategia de búsqueda y selección de artículos según fases PRISMA Preferred Reporting Items for Systematic reviews and Meta-Analyses. 
Identificación. Se realizó una búsqueda exhaustiva de la literatura científica publicada en PubMed, Scielo y Lilacs, combinando los términos Anaplasma o Anaplasmosis con los sinónimos que aparecen en los descriptores en Ciencias de la Salud (DeCS) para prevalencia, es decir, frecuencia, ocurrencia, epidemiología, vigilancia, brotes e incidencia, para un total de 14 estrategias de búsqueda diferentes en español e inglés.

Tamización. En esta fase se aplicaron los criterios de inclusión de tener los términos de búsqueda en título/ resumen, ser un estudio observacional de prevalencia, en caninos como población central y con el reporte explícito de la prevalencia, es decir, la población y el número de positivos; no se aplicaron restricciones de tiempo en la búsqueda y selección, aunque la primera publicación hallada es de 2001, y prospectivamente la última actualización del protocolo de búsqueda se realizó en abril del 2018, por lo que se delimitó como ventana de tiempo de este estudio el periodo 2000-2018. Algunas sintaxis usadas en la búsqueda y selección fueron: (Anaplasma[Title]) AND Prevalence[Title/Abstract], (Anaplasmosis[Title]) AND Ocurrence[Title/Abstract], (ti: (anaplasma)) AND (ab: (prevalencia)).

Elección. Se excluyeron los estudios que no eran investigaciones originales tipo editoriales o revisiones de tema, estudios con información incompleta como no incluir el nombre de la prueba diagnóstica usada, estudios de caso o series de casos con bajo tamaño de muestra (10 o menos).

Inclusión. Se realizó una síntesis cualitativa y cuantitativa de los estudios que cumplieron el protocolo anterior, con dichos artículos se realizó una base de datos en un archivo plano de Excel con las variables título, autores, año de publicación, país de realización, número de caninos evaluados, número de caninos positivos y prueba diagnóstica usada; en algunos estudios fue posible analizar variables adicionales como la especie infectante y la presencia de coinfecciones.

Análisis de reproducibilidad y evaluación de la calidad metodológica. Se garantizó la reproducibilidad de la búsqueda y selección de los estudios por consenso y remisión a un tercero, para la reproducibilidad de la extracción de la información de los artículos incluidos se hizo un diligenciamiento de la base de datos en Excel de manera independiente por dos investigadores hallando un índice kappa de 1.00 en las variables cualitativas y un coeficiente de correlación intraclase de 1.00 para las cuantitativas. Para la evaluación de la calidad metodológica de los estudios se aplicaron los criterios contenidos en la guía STROBE STrengthening the Reporting of OBservational studies in Epidemiology para estudios transversales.

Análisis de la información. la descripción de las variables del estudio se hizo con frecuencias (absolutas y relativas), se construyó un Forest Plot para graficar la prevalencia de infección reportada en cada estudio, agrupados según la prueba diagnóstica, con sus intervalos de confianza del $95 \%$. Además, se estimaron prevalencias específicas por periodo de estudio, continente y prueba diagnóstica, y en los casos que fue posible, se estimó la prevalencia específica de infección por $A$. platys y $A$. phagocytophilum con sus intervalos de confianza del $95 \%$ mediante un modelo de efectos aleatorios (que incluye en la estimación la variabilidad intra e inter estudios) dada la heterogeneidad en los reportes individuales según esta coeficiente RI ( $\mathrm{I}^{2}$ Proporción de la varianza total debida a la varianza entre estudios). Las prevalencias específicas de cada especie se compararon con la Prueba $Z$ o intervalo de confianza para la diferencia de proporciones.

Aspectos éticos. Con base en la Resolución 8430 del Ministerio de Salud de Colombia 1993, el estudio se clasifica como una investigación sin riesgo, dado el uso de fuentes documentales o secundarias.

\section{RESULTADOS}

En la búsqueda inicial se hallaron 1.314 estudios en todas las bases de datos y con la totalidad de estrategias de búsqueda, de éstos se tamizaron 408 artículos que incluían los términos de búsqueda en título, resumen o ambos; sólo 30 estudios cumplieron el protocolo de búsqueda e inclusión de estudios (Figura 1).

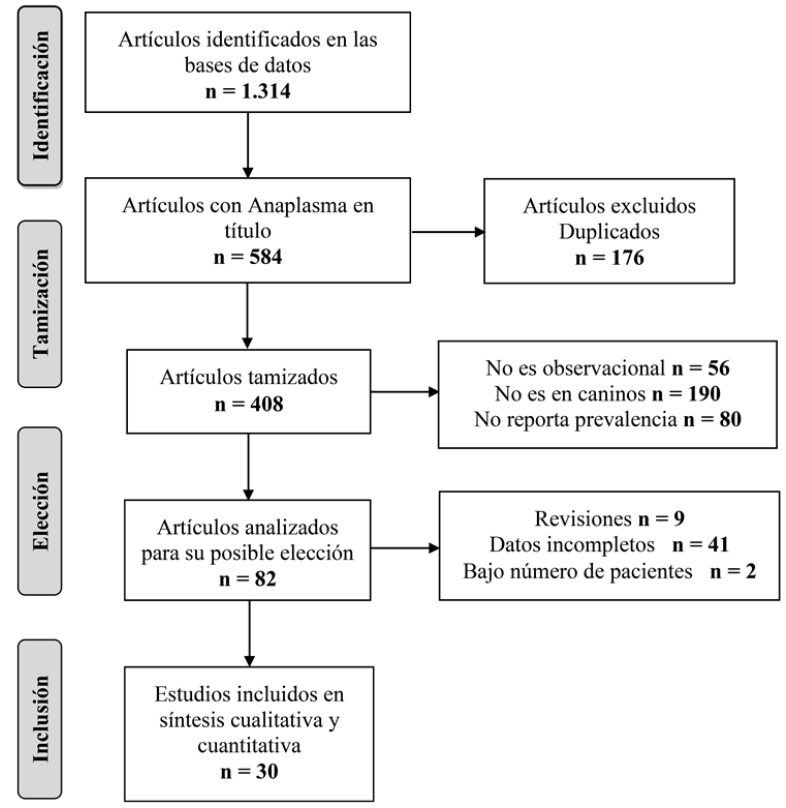

Figura 1. Flujograma de selección de los estudios.

Los estudios se publicaron entre 2005 y 2017 con mayor proporción de publicaciones a partir del 2011 con un $66.7 \%(n=20)$. El $43.3 \%(n=13)$ se realizó en países de Europa, el 36.7\% $(n=11)$ de América, $13.3 \%(n=4)$ de Asia y $6.7 \%$ de África $(n=2)$; los países con el mayor número de estudios fueron Brasil, Estados Unidos y Alemania. El 56.6\% $(n=17)$ de los estudios empleó PCR, $36.6 \%(n=11)$ ELISA y el $20.0 \%(n=6)$ IFI; uno usó simultáneamente PCR y ELISA, y tres PCR e IFI (Tabla 1).

La revisión sistemática se desarrolló en una población de 18.472 caninos, con un $70.7 \%(n=13.067)$ en el periodo 2011-2017; 55.4\% $(n=10.237)$ en Europa, $29.5 \%$ $(n=5.442)$ en América, $13.0 \%(n=2.397)$ en Asia y $2.1 \%$ $(n=396)$ en África. $65.2 \%(n=12.044)$ de los caninos se tamizó o diagnosticó con ELISA, 30.1\% $(n=5.554)$ con PCR y $13.3 \%(n=2.453)$ con IFI (Tabla 1$)$. 
Tabla 1. Descripción de los estudios según año, país, prueba y número de individuos incluidos.

\begin{tabular}{|c|c|c|c|c|}
\hline Autor & Año & País & Prueba & $\mathbf{N}$ \\
\hline Haibin H (16) & 2005 & Venezuela & PCR & 43 \\
\hline Barutzki D (17) & 2006 & Alemania & IFI & 1.124 \\
\hline Levi O (18) & 2006 & Israel & IFI & 195 \\
\hline Solano L (19) & 2006 & Italia & PCR & 460 \\
\hline Jensen J (20) & 2007 & Alemania & PCR e IFI & 111 \\
\hline Beall M (21) & 2008 & Estados Unidos & PCR y ELISA & 731 \\
\hline M'Ghirbi Y (22) & 2009 & Túnez & IFI & 286 \\
\hline Pantchev N (23) & 2009 & Francia & ELISA & 919 \\
\hline Barber R (24) & 2010 & Estados Unidos & PCR & 109 \\
\hline Sakamoto L (25) & 2010 & Japón & PCR & 1.427 \\
\hline Carrade D (26) & 2011 & Estados Unidos & ELISA & 2.431 \\
\hline Kohn B (27) & 2011 & Alemania & IFI y PCR & 522 \\
\hline Barth C (28) & 2012 & Alemania & ELISA & 448 \\
\hline Cardoso L (29) & 2012 & Portugal & ELISA & 1.185 \\
\hline Ferreira G (30) & 2012 & Brasil & PCR & 256 \\
\hline Mircean V (31) & 2012 & Rumania & ELISA & 1.146 \\
\hline Xia Z (32) & 2012 & China & ELISA & 600 \\
\hline Berzina I (33) & 2013 & Letonia & ELISA & 470 \\
\hline Costa L (34) & 2013 & Brasil & PCRq & 511 \\
\hline Ebani V (35) & 2013 & Italia & PCR e IFI & 215 \\
\hline Lasta C (36) & 2013 & Brasil & PCR & 199 \\
\hline Santos H (37) & 2013 & Brasil & PCR & 398 \\
\hline Volgina N (38) & 2013 & Rusia & ELISA & 522 \\
\hline Kramer F (39) & 2014 & Polonia & ELISA & 3.094 \\
\hline Lanza M (40) & 2014 & España & PCR & 21 \\
\hline McCown M (41) & 2014 & Colombia & ELISA & 498 \\
\hline Santamaria A (42) & 2014 & Panamá & PCR & 201 \\
\hline Dahmani M (43) & 2015 & Guayana & PCR & 65 \\
\hline Dahmani M (44) & 2015 & Algeria & PCR & 110 \\
\hline Yuasa Y (45) & 2017 & Taiwán & PCR & 175 \\
\hline
\end{tabular}

Los estudios presentaron buena calidad metodológica al cumplir $70 \%$ o más de los criterios de la guía STROBE; sin embargo, algunos criterios son poco explícitos en los estudios como los referidos al control de sesgos de selección e información, la realización de análisis adicionales que mejoren la exploración de factores asociados y la discusión de las posibles generalizaciones de resultados (Figura 2 ).

En los 2.453 individuos tamizados con IFI se halló una seroprevalencia de infección estadísticamente mayor a las demás pruebas con un $39.0 \%$ (IC95\%= 37.0-41.0), en 12.044 caninos en los cuales se aplicó ELISA la seroprevalencia fue $9.3 \%$ (IC95\% $=8.8-9.8)$ y en los 5.096 caninos analizados con PCR fue 7.1\% (IC95\%=6.4-7.8); en todas las pruebas se halló una elevada heterogeneidad con prevalencia entre $0.0 \%$ y $50.1 \%$ (Figura 3 ).

Con base en el periodo de estudio, se halló una menor prevalencia en los estudios más recientes (entre 2011 y 2017), con excepción de los estudios basado en PCR en los cuales se halló una prevalencia de $2.4 \%$ (IC95\% $=1.8$ 3.0) en las publicaciones del periodo 2001-2010 en contraste con un $11.3 \%$ (IC95\%=10.1-12.5) entre 2011 y 2017 (Figura 4).

Según el lugar de estudio, se halló una prevalencia estadísticamente mayor en África, aunque al analizar sólo la prevalencia basada en PCR fue estadística mayor

\begin{tabular}{lr}
\hline Criterio & \% de estudios que cumplen \\
\hline Título/ Resumen & $\mathbf{9 7}$ \\
Fundamentación & $\mathbf{1 0 0}$ \\
Objetivo & $\mathbf{1 0 0}$ \\
Diseño del estudio & $\mathbf{9 3}$ \\
Contexto & $\mathbf{1 0 0}$ \\
Participantes & $\mathbf{8 3}$ \\
Definición de variables & $\mathbf{7 3}$ \\
Fuente de datos & $\mathbf{9 3}$ \\
Control de sesgos & $\mathbf{5 3}$ \\
Tamaño de muestra & $\mathbf{1 0 0}$ \\
Variables cuantitativas & $\mathbf{6 3}$ \\
Análisis estadísticos & $\mathbf{6 7}$ \\
Resultados de los participantes & $\mathbf{8 7}$ \\
Resultados principales & $\mathbf{8 3}$ \\
Análisis adicionales & $\mathbf{2 3}$ \\
Discusión de resultados clave & $\mathbf{1 0 0}$ \\
Limitaciones & $\mathbf{5 7}$ \\
Interpretaciones & $\mathbf{8 7}$ \\
Discusión de la generalización & $\mathbf{7}$ \\
Financiación & $\mathbf{6 0}$ \\
\hline &
\end{tabular}

Figura 2. Evaluación de la calidad metodológica de los estudios incluidos.

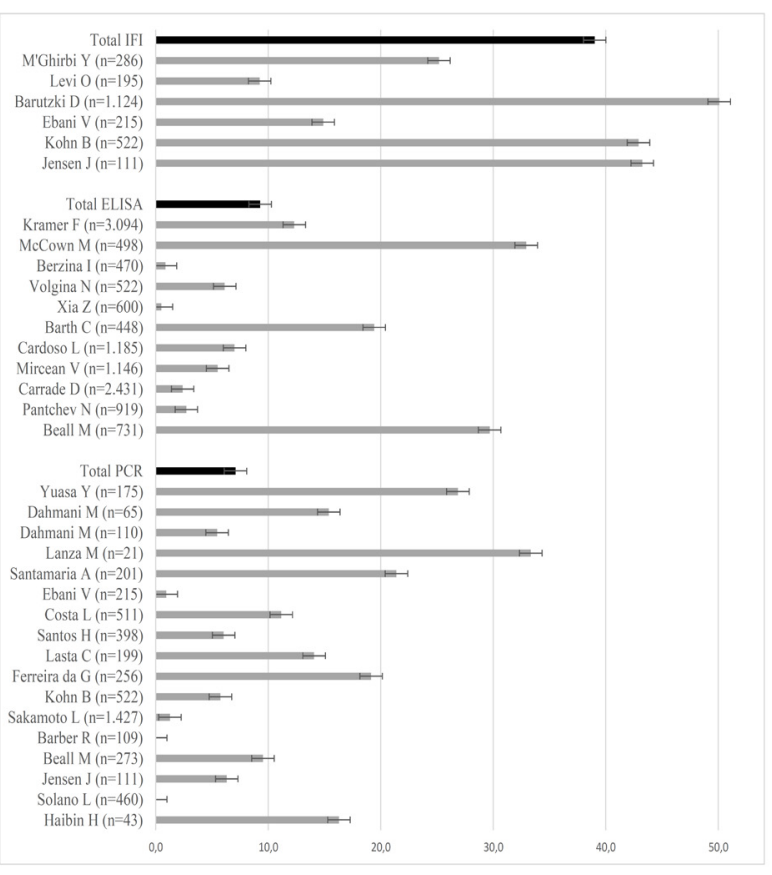

Figura 3. Prevalencia global de infección por técnica diagnóstica e individual de cada estudio, con sus intervalos de confianza del $95 \%$.

Nota: el número total resulta mayor a la población de caninos evaluados por los estudios que aplicaron simultáneamente dos pruebas. 
en América con un 11.9\% (IC95\%=10.5-13.3) frente a África con un 5.5\% (IC95\%=1.2-9.7), Asia $4.1 \%$ $($ IC95\%=3.1-5.1) y Europa $3.5 \%($ IC95\%=2.5-4.5) (Figura 4).

En los estudios incluidos fue deficiente el reporte de prevalencias específicas según la zona de procedencia, la especie implicada, la frecuencia de coinfecciones y la presencia o ausencia de signos en los caninos.

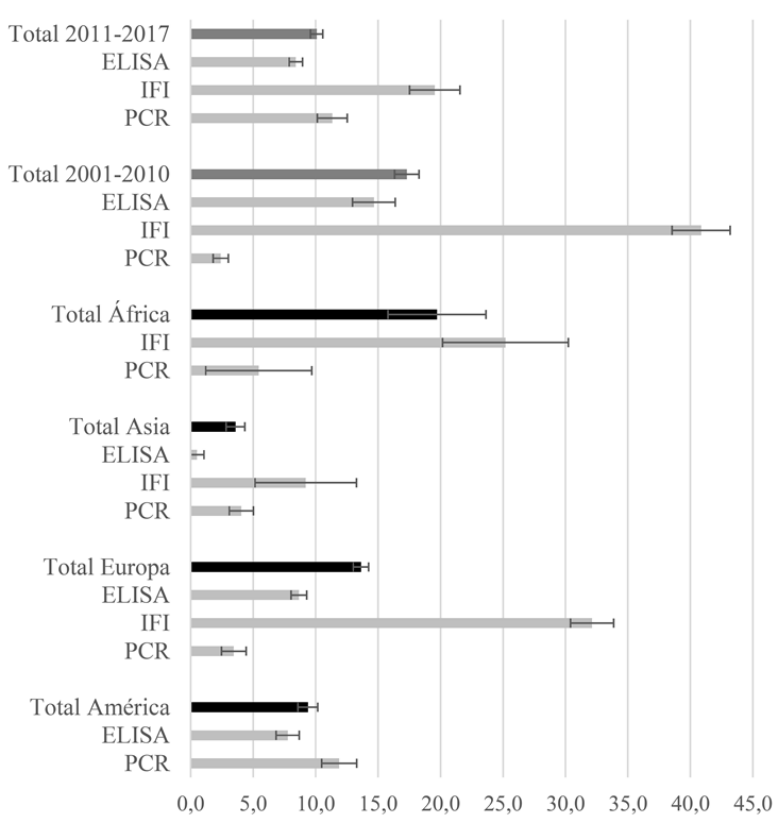

Figura 4. Prevalencia de infección según periodo, lugar y prueba diagnóstica.

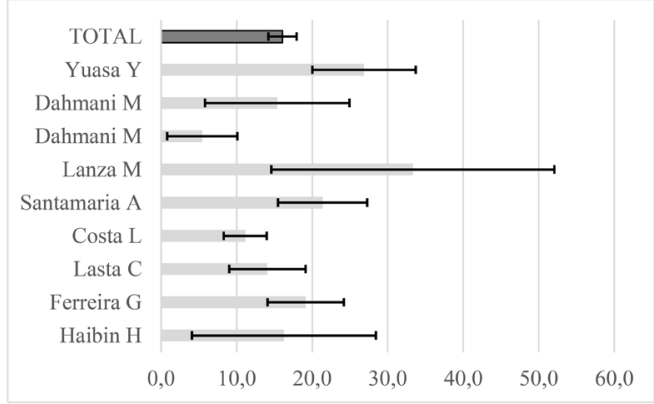

Prevalencia de $A$. platys con PCR.

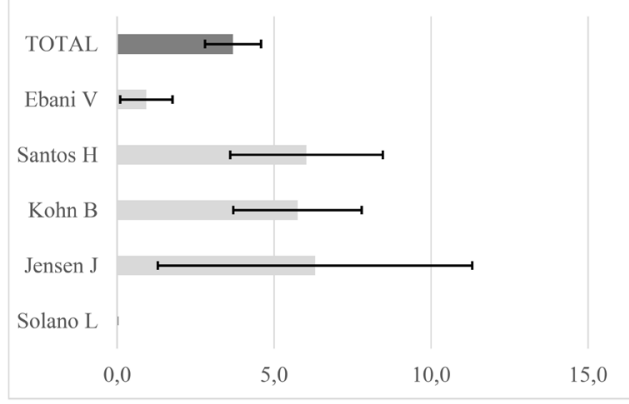

Prevalencia de A. phagocytophilum con PCR.
En este sentido, algunos estudios reportaron una mayor prevalencia en la zona rural durante la temporada de lluvias, seguido de zonas rurales en temporada seca y menor en las zonas urbanas (34).

En los estudios que reportaron la prevalencia de infección según la presentación de signos, no se observaron diferencias significativas con un $44.9 \%$ en perros con signos y $41.9 \%$ en los asintomáticos (20); $46.9 \%$ en caninos enfermos y $39.8 \%$ en animales sanos (27); $4.5 \%$ en caninos sanos y $9.2 \%$ en animales con enfermedades caninas de transmisión vectorial (30). Sólo un estudio reportó la prevalencia de $A$. bovis con un $1.3 \%(\mathrm{IC} 95 \%=0.5-1.6)(25)$.

La prevalencia de $A$. platys en 1.581 individuos evaluados con PCR fue heterogénea (coeficiente $R I=0.90$ ) con estudios que reportaron prevalencias entre $5.5 \%$ y $33.3 \%$; para una prevalencia global de $16.1 \%$ (IC95\%=14.2-17.9); ésta resultó estadísticamente mayor a la prevalencia de $A$. phagocytophilum que en 1.706 caninos evaluados con PCR fue 3.7\% (IC95\%= 2.8-4.6), lo que equivale a una diferencia que oscila entre $10.3 \%$ y $14.5 \%$ (Estadístico $Z$ para la diferencia de proporciones $=11.95 . \mathrm{Vp}=0.000)($ Figura 5).

A su vez, la prevalencia de $A$. phagocytophilum fue estadísticamente menor al utilizar PCR en comparación con los estudios que usaron ELISA e IFI; en 10.859 caninos analizados con ELISA se halló una seroprevalencia de $9.4 \%$ (IC95\%=8.9-10.0) con una diferencia de proporciones de $4.7 \%$ a $6.8 \%$ (Estadístico $Z=7.8$. $\mathrm{V} p=0,000)$ frente a PCR, y en que en 2.453 caninos diagnosticados con IFI la seroprevalencia fue $39.0 \%$ (IC95\% = 37.0-40.9) lo que resulta entre $33.1 \%$ y $37.5 \%$ mayor que los hallazgos con PCR (Estadístico $\mathrm{Z}=26.0 . \mathrm{Vp}=0,000$ ). Finalmente, la seroprevalencia de $A$. phagocytophilum con IFI con IFI fue $27.5-31.6 \%$ mayor, frente al uso de ELISA (Estadístico $Z=37.1$. $\mathrm{Vp}=$ 0.000) (Figura 5).

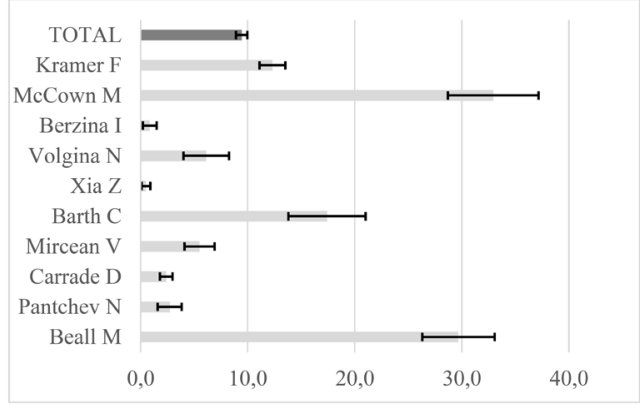

Prevalencia A. phagocytophilum con ELISA

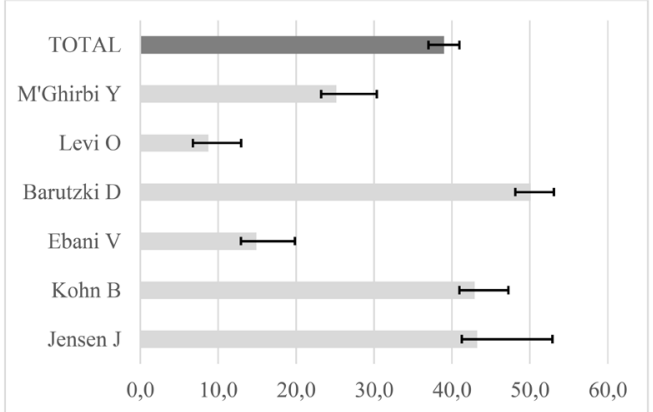

Prevalencia A. phagocytophilum con IFI.

Figura 5. Metanálisis (Forest Plot) de la prevalencia de A. platys y A. phagocytophilum según la prueba diagnóstica. 


\section{DISCUSIÓN}

Se incluyeron 30 publicaciones en 13 años, donde se evaluó la infección en 18.472 caninos, la mayoría de Brasil, Estados Unidos y Alemania, con buena calidad metodológica, lo que evidencia una elevada validez de este metanálisis. En países como Brasil las razones pueden estar dadas por su ubicación geográfica y su clima, dado que las infecciones por Anaplasma spp., se han reportado con mayor incidencia en áreas tropicales y subtropicales (43). Los climas húmedos tropicales proporcionan un medio ambiente adecuado para la presencia de vectores tales como garrapatas y mosquitos. Con respecto a los reservorios naturales, existe una fuerte variación geográfica entre diferentes enfermedades transmitidas por garrapatas. Las poblaciones caninas son susceptibles a la mayor parte de los patógenos transmitidos por las garrapatas que infectan los mamíferos, incluyendo los seres humanos, por lo que los perros son grandes reservorios y centinelas adecuados para las enfermedades infecciosas y zoonóticas (41).

En países Europeos, como Alemania, la anaplasmosis se ha reportado como una zoonosis emergente. Anaplasma spp., muestra una amplia distribución geográfica, pues se extiende por todo el hemisferio norte, desde Canadá hasta China. En Europa, A. phagocytophilum se distribuye por todo el continente. Prueba de ello es la existencia de personas seropositivas en numerosos países, así como la presencia del patógeno en garrapatas y en macro y micromamíferos de la mayoría de los países europeos. En cuanto a la distribución temporal Anaplasma spp., tanto en Europa como en Estados Unidos, se observa una clara estacionalidad. La mayoría de los casos se registran en el verano y a finales del otoño, periodo este en el que coincide la aparición de las ninfas y de los adultos de las garrapatas. La diferencia entre seropositivos y casos clínicos se atribuye a diagnósticos incorrectos y a la existencia de variantes de patógenos de Anaplasma spp. (13).

En los estudios que usaron IFI se halló una prevalencia de $39.0 \%$, en ELISA $9.3 \%$ y en PCR $7.1 \%$, con una elevada heterogeneidad atribuible a los lugares de estudios y la prueba per se, lo que demuestra el riesgo de hallar falsos positivos en los programas de tamización basados en la estimación de la seroprevalencia. Para establecer la cantidad de perros que presentan infecciones activas, pasadas o persistentes con anaplasmosis, se debe elegir el método más adecuado, se han reportado resultados positivos en la IFI de Anaplasma spp., y resultado negativo en PCR, es entonces cuando se debe determinar si la infección es pasada con presencia de anticuerpos y ausencia de antígenos $(20,27,35)$.

La visualización al microscopio de extendidos de sangre, con tinción giemsa es la técnica diagnóstica de referencia y el método más común para la identificación de Anaplasma spp. en animales con sintomatología clínica; sin embargo, en fases crónicas, en individuos asintomáticos o en el estadio de portador, no expresa una elevada parasitemia que permita su detección con la tinción. Es un método económico y sencillo, capaz de detectar niveles de parasitemia de 0.1 a $0.2 \%$, es decir, sólo pude detectar niveles mayores a $10^{6}$ eritrocitos infectados por mililitro de sangre, además, resulta tedioso, no apropiado para un gran número de muestras e incapaz de diferenciar especies (48).
La IFI, es uno de los más utilizados y frecuentemente se ha considerado una prueba sensible; sin embargo, en ocasiones se considera poco útil por las reacciones falsas positivas. Por su parte, la detección de anticuerpos por ELISA es sensible, específica y brinda la posibilidad de una mejor interpretación de los resultados cuando se compara con las técnicas antes mencionadas, permite conocer el estado de inmunitario de las poblaciones de animales y determinar la seroprevalencia de la infección; sin embargo, se han reportado casos de reactividad cruzada entre $A$. platys y $A$. phagocytophilum, por ser especies relacionadas que comparten epítopos antigénicos (48).

Por último, la PCR es la prueba de mayor sensibilidad y especificidad, lo que permite superar limitaciones de otras pruebas, como la alta proporción de resultados falsos y las reacciones cruzadas entre especies, lo que resulta esencial para apoyar el diagnóstico clínico, evaluar el estado de portador de los animales y estimar la prevalencia de la infección general y por especie (48).

Con base en los estudios que emplearon PCR se halló una prevalencia estadísticamente mayor en América con un $11.9 \%$, frente a África con $5.5 \%$, Asia $4.1 \%$ y Europa 3.5\%; lo que demuestra una alta heterogeneidad atribuible al país de estudio, al tiempo que evidencia la necesidad de disponer de estudios para cada contexto, con los cuales se mejore el conocimiento de la relación de las características del ambiente, los hospedadores y los vectores específicos de cada lugar (aspectos no descritos en los estudios sistematizados). Esta recomendación toma mayor importancia al considerar otras fuentes de variación en la distribución de la infección como el tipo de población seleccionada, la endemicidad del lugar de estudio, la presencia o ausencia de signos clínicos y la exigencia o no de notificación por las autoridades sanitarias de cada país $(20,27,35)$.

La prevalencia de $A$. platys con PCR fue $16.1 \%$ y de $A$. phagocytophilum $3.7 \%$, corroborando la primera especie como el principal agente causal en caninos, a diferencia de otras como, A. phagocytophilum que predomina en humanos, caballos, burros, jabalis y pequeños rumiantes como cabras y ovejas $(14,46), A$. marginale y $A$. centrale en bovinos, $A$. ovis causante de un padecimiento limitado a ovinos y caprinos (47).

La principal coinfección fue con Ehrlichia canis y Borrelia burgdorferi. Para el primer agente, un estudio en Brasil reportó un $16.4 \%$ de $E$. canis, $19.4 \%$ de $A$. Platys y $5.5 \%$ de coinfección por ambos microorganismos (30); en Panamá se informó una prevalencia de $64.2 \%$ de $E$. canis, $21.4 \%$ de $A$. platys y un $7.5 \%$ de coinfecciones por ambos (42) y en tres ciudades de Colombia se reportaron prevalencias de $25 \%$ para $E$. canis, $11 \%$ para $A$. phagocytophilum y coinfección del 6\% (41). En el caso de $B$. burgdorferi, un estudio en Alemania halló seroprevalencias de $4.9 \%$ con este agente, $19.4 \%$ con A. phagocytophilum y $2,0 \%$ de coinfección (28), el Latvia la seroprevalencia de coinfección fue del $36 \%$ en los caninos infectados con $B$. burgdorferi (33) y en Polonia la coinfección por $A$. phagocytophilum y $B$. burgdorferi fue del $1.7 \%$ (39). Estos datos demuestran la importancia de utilizar técnicas que permitan la identificación de especie y el diagnóstico diferencial, principalmente en casos de anemia y trombocitopenia. 
Entre las limitaciones se destaca el hecho que en los estudios incluidos fue deficiente o muy heterogéneo el reporte de prevalencias específicas según la zona de procedencia, la especie implicada, la frecuencia de coinfecciones, la presencia o ausencia de signos en los caninos, entre otras variables independientes que resultan útiles en los estudios de prevalencia para identificar potenciales factores asociados y consolidar hipótesis para estudios analíticos.

En conclusión se halló una elevada prevalencia de infección global, con mayor importancia de $A$. platys, en un bajo número de publicaciones en el ámbito mundial y con una elevada heterogeneidad en la ocurrencia de la infección según el país, la técnica diagnóstica y la especie implicada; información relevante para fomentar el desarrollo de investigaciones epidemiológicas y acciones de sanitarias en población canina.

Financiación. Universidad de Antioquia, Universidad Cooperativa de Colombia.

\section{Conflicto de intereses}

Ninguno de los autores declara conflictos de interés para la publicación de este estudio.

\section{REFERENCIAS}

1. Carrade D, Foley J, Borjesson D, Sykes J. Canine granulocytic Anaplasmosis: a review. J Vet Intern Med. 2009; 23(6):1129-1141. https://doi. org/10.1111/j.1939-1676.2009.0384.x

2. Dolz G, Ábrego L, Romero L, Campos L, Bouza L, Jiménez $A$. Ehrlichiosis and anaplasmosis in Costa Rica. Acta Méd Costarric. 2013; 55(Suppl. 1): 3440. https://www.scielo.sa.cr/scielo.php?script=sci arttext\&pid $=$ S0001-60022013000400008

3. Pujalte G, Marberry S, Libertin C. Tick-Borne Illnesses in the United States. Prim Care. 2018; 45(3):379-391. https://doi.org/10.1016/j. pop.2018.05.011

4. Soto K. Determinación de la prevalencia de anaplasmosis en el ganado bovino faenado en la empresa Metropolitana de Rastro de Quito mediante la aplicación de las técnicas de diagnóstico: microscopía de frotis sanguíneos, PCR y cELISA. Ecuador: Escuela Politécnica del Ejército, Ingeniería en Biotecnología; 2010. http://repositorio.espe. edu.ec/handle/21000/2846

5. Mateus T, Castro A, Ribeiro J, Vieira M. Multiple Zoonotic Parasites Identified in Dog Feces Collected in Ponte de Lima, Portugal - A Potential Threat to Human Health. Int J Environ Res Public Health. 2014; 11(9):9050-9067. https://doi.org/10.3390/ ijerph110909050

6. Troncoso I, Fisher C, Villarroel C, Herzberg D. Case report: Anaplasma phagocytophilum in a dog. Hospitales veterinarios. 2014, 6(2):4146. http://www.rhv.cl/index.php?option=com docman\&task $=$ doc download\&gid $=83 \&$ Itemid $=$

7. Berzina I, Krudewig C, Silaghi C, Matise I, Ranka R, Müller N, et al. Anaplasma phagocytophilum DNA amplified from lesional skin of seropositive dogs. Ticks Tick Borne Dis. 2014; 5(3):329-35. https:// doi.org/10.1016/j.ttbdis.2013.12.010
8. Stuen S, Granquist EG, Silaghi C. Anaplasma phagocytophilum a widespread multi-host pathogen with highly adaptive strategies. J Front Cell Infect Microbiol. 2013; 22:3-31. https://doi.org/10.3389/ fcimb. 2013.00031

9. Greene C, Enfermedades infecciosas del perro y el gato. 3ed. Buenos Aires: Argentina; 2008.

10. Gaunt S, Beall M, Stillman B, Lorentzen L, Diniz P, Chandrashekar R, Breitschwerdt E. Experimental infection and co-infection of dogs with Anaplasma platys and Ehrlichia canis: hematologic, serologic and molecular findings. Parasit Vectors. 2010; 3(1):1-10. https://doi.org/10.1186/1756-3305-3-33

11. Vargas $G$, Rogerio $M$, Cendales D, Gonçalves $L$, Hoeppner $M$, et al. Molecular detection of Anaplasma species in dogs in Colombia. Rev Bras Parasitol Vet. 2016; 25(4):459-464. https://doi. org/10.1590/s1984-29612016066

12. Carelli G, Decaro N, Lorusso A, Elia G , Lorusso $E$, Mari $V$, et al. Detection and quantification of Anaplasma marginale DNA in blood samples of cattle by real-time PCR. Vet Microbiol. 2007; 124(1):107-114. https://doi.org/10.1016/j. vetmic.2007.03.022

13. Pérez R, Fernández $P$, Encinas A. Garrapatas y anaplasmosis granulocítica humana. Rev Ibérica Parasitología. 2006; 66(1):17-29. http:// bibliotecavirtual.ranf.com/es/catalogo imagenes/ grupo. $\mathrm{cmd}$ ?path $=1001734$

14. Oteo J, Brouqui P. Ehrlichiosis and human anaplasmosis. Enferm Infecc Microbiol Clin. 2005; 23(6):375-380. https://doi.org/10.1157/13076178

15. González de Dios J. Revisión sistemática y metanálisis (I): conceptos básicos. Evid Pediatr. 2007; 3(4):107. https://evidenciasenpediatria.es/ articulo/5204/revision-sistematica-y-metaanalisisi-conceptos-basicos 
16. Huang $H$, Unver A, Perez M, Orellana N, Rikihisa Y. Prevalence and molecular analysis of Anaplasma platys in dogs in Lara, Venezuela. Braz J Microbiol. 2005; 36(3):211-216. https://doi.org/10.1590/ $\underline{\text { s1517-83822005000300002 }}$

17. Barutzki D, De Nicola A, Zeziola M, Reule M. Seroprevalence of Anaplasma phagocytophilum infection in dogs in Germany. Berl Munch Tierarztl Wochenschr. 2006; 119(7-8):342-347. https:// www.ncbi.nlm.nih.gov/pubmed/17009720

18. Levi O, Waner T, Baneth G, Keysary A, Bruchim Y, Silverman J, Harrus S. Seroprevalence of Anaplasma phagocytophilum among healthy dogs and horses in Israel. J Vet Med. 2006; 53(2):78-80. https:// doi.org/10.1111/j.1439-0450.2006.00911.x

19. Solano L, Trotta M, Razia L, Furlanello T, Caldin M. Molecular survey of Ehrlichia canis and Anaplasma phagocytophilum from blood of dogs in Italy. Ann N Y Acad Sci. 2006; 1078:515-518. https://doi. org/10.1196/annals.1374.101

20. Jensen J, Simon D, Escobar H, Soller J, Bullerdiek J, Beelitz P, et al. Anaplasma phagocytophilum in dogs in Germany, Alemania. Zoonoses Public Health. 2007; 54(2):94-101. https://doi.org/10.1111/ j.1863-2378.2007.01028.x

21. Beall M, Chandrashekar R, Eberts MD, Cyr KE, Diniz $\mathrm{PP}$, Mainville $\mathrm{C}$, et al. Serological and molecular prevalence of Borrelia burgdorferi, Anaplasma phagocytophilum, and Ehrlichia species in dogs from Minnesota. Vector Borne Zoonotic Dis. 2008; 8(4):455-464. https://doi.org/10.1089/ vbz.2007.0236

22. M'ghirbi Y, Ghorbel A, Amouri M, Nebaoui A, Haddad $S$, Bouattour A. Clinical, serological, and molecular evidence of ehrlichiosis and anaplasmosis in dogs in Tunisia. Tunez. Parasitol Res. 2009; 104(4):767-74. https://doi.org/10.1007/s00436-008-1253-4

23. Pantchev N, Schaper R, Limousin S, Norden N, Weise M, Lorentzen L. Occurrence of Dirofilaria immitis and tick-borne infections caused by Anaplasma phagocytophilum, Borrelia burgdorferi sensu lato and Ehrlichia canis in domestic dogs in France: results of a countrywide serologic survey. Parasitol Res. 2009; 105 (Suppl. 1):101-114. https://doi.org/10.1007/s00436-009-1501-2

24. Barber R, Li Q, Diniz P, Porter B, Claiborne M, Levine J, et al. Evaluation of brain tissue or cerebrospinal fluid with broadly reactive polymerase chain reaction for Ehrlichia, Anaplasma, spotted fever group Rickettsia, Bartonella, and Borrelia species in canine neurological diseases (109 cases). J Vet Intern Med. 2010; (2):372-378. https://doi. org/10.1111/j.1939-1676.2009.0466.x

25. Sakamoto L, Ichikawa Y, Sakata Y, Matsumoto K, Inokuma $\mathrm{H}$. Detection of Anaplasma bovis DNA in the peripheral blood of domestic dogs in Japan. Jpn J Infect Dis. 2010; 63(5):349-52. https://www. ncbi.nlm.nih.gov/pubmed/20859003
26. Carrade D, Foley J, Sullivan M, Foley C, Sykes J. Spatial distribution of seroprevalence for Anaplasma phagocytophilum, Borrelia burgdorferi, Ehrlichia canis, and Dirofilaria immitis in dogs in Washington, Oregon, and California. Vet Clin Pathol. 2011; 40(3):293-302. https://doi.org/10.1111/j.1939165x.2011.00334.x

27. Kohn B, Silaghi C, Galke D, Arndt G, Pfister K. Infections with Anaplasma phagocytophilum in dogs in Germany. Res Vet Sci. 2011; 91(1):71-6. https://doi.org/10.1016/j.rvsc.2010.08.008

28. Barth C, Straubinger R, Sauter-Louis C, Hartmann K. Prevalence of antibodies against Borrelia burgdorferi sensu lato and Anaplasma phagocytophilum and their clinical relevance in dogs in Munich, Germany. Berl Munch Tierarztl Wochenschr. 2012; (7-8):337-44. https://www.ncbi.nlm.nih.gov/ pubmed/22919928

29. Cardoso L, Mendão C, Madeira de Carvalho L.Prevalence of Dirofilaria immitis, Ehrlichia canis, Borrelia burgdorferi sensu lato, Anaplasma spp. and Leishmania infantum in apparently healthy and CVBDsuspect dogs in Portugal--a national serological study Portugal. Parasit Vectors. 2012; 5(62):1-9. https:// doi.org/10.1186/1756-3305-5-62

30. da Silva G, Benitez A, Girotto A, Tarod A, Vidotto M, Garcia J, Freitas J, Headley S, Vidotto O. Occurrence of Ehrlichia canis and Anaplasma platys in household dogs from northern Parana. Rev Bras Parasitol Vet. 2012 ; 21(4):379-85 https://doi. org/10.1590/s1984-29612012005000009

31. Mircean $V$, Dumitrache $M$, Györke $A$, Pantchev N, Jodies R, Cozma V, el al. Seroprevalence and geographic distribution of Dirofilaria immitis and tick-borne infections (Anaplasma phagocytophilum, Borrelia burgdorferi sensu lato, and Ehrlichia canis) in dogs from Romania Vector Borne Zoonotic Dis. 2012; 12(7):595-604. https://doi.org/10.1089/ vbz.2011.0915

32. Xia Z, Yu D, Mao J, Zhang Z, Yu J. The occurrence of Dirofilaria immitis, Borrelia burgdorferi, Ehrlichia canis and Anaplasma phagocytophium in dogs in China. J Helminthol. 2012; 86(2):185-189. https:// doi.org/10.1017/s0022149×11000198

33. Berzina, I. Matise I. Seroprevalence against Borrelia burgdorferi sensu lato and occurence of antibody co-expression with Anaplasma phagocytophilum in dogs in Latvia. Ir Vet J. 2013; 66(1):1-3. https:// doi.org/10.1186/2046-0481-66-9

34. Costa L, Rembeck K, Passos L, Ribeiro M. Factors associated with epidemiology of Anaplasma platys in dogs in rural and urban areas of Minas Gerais State, Brazil, Preventive Veterinary Medicine. 2013; 109(3-4):321-326. https://doi.org/10.1016/j. prevetmed.2012.10.011 
35. Ebani V, Bertelloni F, Turchi B, Cerri D. Serological and molecular survey of Anaplasma phagocytophilum in Italian hunting dogs. Ann Agric Environ Med. 2013; 20(2):289-292. https://www.ncbi.nlm.nih. gov/pubmed/23772578

36. Lasta C, Do Santos A, Messick J, Oliveira S, Biondo $A$, Viera $R$, et al. Molecular detection of Ehrlichia canis and Anaplasma platys in dogs in Southern Brazil. Rev Bras Parasitol Vet. 2013; 22(3):360-366. https://doi.org/10.1590/s198429612013000300007

37. Santos A, Thome S, Baldani C, Silva C, Peixoto $M$, Pires $M$, et al. Molecular epidemiology of the emerging zoonosis agent Anaplasma phagocytophilum (Foggie, 1949) in dogs and ixodid ticks in Brazil. Parasit Vectors. 2013; 11(6):348358. https://doi.org/10.1186/1756-3305-6-348

38. Volgina N, Romashov B, Romashova N, Shtannikov A. Prevalence of borreliosis, anaplasmosis, ehrlichiosis and Dirofilaria immitis in dogs and vectors in Voronezh Reserve (Russia) Reserva Voronezh, Comp Immunol Microbiol Infect Dis. 2013; 36(6):567-574. https://doi.org/10.1016/j. cimid.2013.08.003

39. Krämer F, Schaper R, Schunack B, Połozowski A, Piekarska J, Szwedko A, et al. Serological detection of Anaplasma phagocytophilum, Borrelia burgdorferi sensu lato and Ehrlichia canis antibodies and Dirofilaria immitis antigen in a countrywide survey in dogs in Poland. Parasitol Res. 2014; 113(9):3229-3239. https://doi.org/10.1007/ s00436-014-3985-7

40. Lanza M, Zieger U, Qurollo B, Hegarty B, Pultorak E, Kumthekar $S$, et al. Intraoperative bleeding in dogs from Grenada seroreactive to Anaplasma platys and Ehrlichia canis. J Vet Intern Med. 2014; 28(6):17021707. https://doi.org/10.1111/jvim.12442

41. McCown, M, Monterroso V, Cardona W. Surveillance for Ehrlichia canis, Anaplasma phagocytophilum, Borrelia burgdorferi, and Dirofilaria immitis in Dogs From Three Cities in Colombia. J Spec Oper Med. 2014; 14(1): 86-90. https://doi.org/10.1007/ s00436-018-6033-1
42. Santamaria A, Calzada J, Saldaña A, Yabsley M, Gottdenker N. Molecular diagnosis and species identification of Ehrlichia and Anaplasma infections in dogs from Panama, Central Americ. Vector Borne Zoonotic Dis. 2014; 14(5):368-370. https://doi. org/10.1089/vbz.2013.1488

43. Dahmani M, Marié J, Mediannikov O, Raoult D, Davoust B. First identification of Anaplasma platys in the blood of dogs from French Guiana. Vector Borne Zoonotic Dis. 2015; 15(2):170-172. https:// doi.org/10.1089/vbz.2014.1720

44. Dahmani M, Loudahi A, Mediannikov O, Fenollar F, Raoult D, Davoust B. Molecular detection of Anaplasma platys and Ehrlichia canis in dogs from Kabylie, Algeria Ticks Tick Borne Dis. 2015; 6(2):198-203. https://doi.org/10.1016/j. ttbdis.2014.12.007

45. Yuasa Y, Tsai Y, Chang C, Hsu T, Chou C. The prevalence of Anaplasma platys and a potential novel Anaplasma species exceed that of Ehrlichia canis in asymptomatic dogs and Rhipicephalus sanguineus in Taiwan. J Vet Med Sci. 2017; 79(9):1494-1502. https://doi.org/10.1292/ jvms.17-0224

46. Párraga M, Gonzatti M, Aso P. Diagnosis of Venezuelan Equine Anaplasmosis by Polymerase Chain Reaction. Revista Científica, FCV-LUZ. 2016; 26(6):366-373. http://www.saber.ula.ve/ bitstream/handle/123456789/43191/articulo3. pdf? sequence $=1$ \&isAllowed $=y$

47. Corona B, Rodriguez M, Martinez S. Anaplasmosis Bovina. Revista electrónica RedVet. 2004; 6(4):127. http://www.veterinaria.org/revistas/redvet/ n040405/040511.pdf

48. Corona González B, Obregón D, Alemán Y, Alfonso $P$, Vega $E$, Díaz A, Martinez $S$. Tendencias en el diagnóstico de la anaplasmosis bovina. Rev Salud Anim. 2014; 36(2):73-79. http://scielo. sld.cu/scielo.php?script $=$ sci_arttext $\&$ pid $=$ S0253$\underline{570 \times 2014000200001}$ 